\title{
Idiopathic perforation of the transverse colon in an adult: a case report and literature review
}

\author{
Shariful Islam ${ }^{2 *}$, Devin Hosein ${ }^{2}$, Patrick Harnarayan ${ }^{1}$ and Dilip Dan ${ }^{1}$ \\ ${ }^{1}$ Department of Clinical Surgical Sciences,University of West Indies,St Augustine, UWI, Trinidad and Tobago, West Indies \\ ${ }^{2}$ San Fernando General Hospital, Trinidad \& Tobago, West Indies
}

\begin{abstract}
True idiopathic perforation of the colon in the adult is both a rare and unusual clinical entity. As the name suggests, there is no identifiable cause making this a diagnosis of exclusion. Due to its rarity, it is difficult to establish causality between the disease and associated patient factors. Mortality of this disease is secondary to the resulting fecal peritonitis and can be reduced by early recognition and timely surgical intervention.
\end{abstract}

\section{Introduction}

Idiopathic perforation of the colon, also referred to as spontaneous colonic perforation is an extremely rare disease in both adults and neonates. It is defined as perforation of the colon without identifiable etiology. As a result, it is a diagnosis of exclusion and can only be made after exhaustion of all other possible causes. We report a case of a 50 year old female who presented to us with colonic perforation without an identifiable cause.

\section{Case description}

A 50 year old female who is a known diabetic presented to our institution with a sudden onset severe abdominal which became generalized with a duration of 6 hours. The pain was described as $10 / 10$ severity, constant, non-radiating, aggravated by movement with relief on lying still. There were no associated factors. Her surgical history was unremarkable with her drug history revealing oral hypoglycemic use with no ASA or NSAID use. Of note, she has a 36 pack year smoking history and drinks 3 nips ( $30 \mathrm{ml}=1 \mathrm{nip}$ ) of puncheon rum (no less than $75 \%$ of alcohol by volume) daily for many years. Examination revealed an ill looking, malnourished female in moderate painful distress. BP: 134/68 mmHg, P: 105, regular, respiratory rate: 20 breaths/min with the remaining vitals within normal limits. Abdominal examination revealed generalized tenderness with board like rigidity, guarding and rebound tenderness. Digital rectal exam was unremarkable. The remaining physical exam was unremarkable. Laboratory results revealed: WBC: 12.5, Hemoglobin: 12.6, Platelet: 159, Cr: 2.3, BUN: 45, electrolytes: within normal limits, ABG: anion gap metabolic acidosis, Abdominal X-ray revealed a pneumoperitoneum and pancreatic calcification (Figure 1).

Following adequate resuscitation, the patient underwent an exploratory laparotomy. Intra-operative findings included: feculent peritonitis with approximately $1.0 \mathrm{~L}$ of free fluid, an approximately $2 \mathrm{~cm}$ perforation in the proximal transverse colon a few $\mathrm{cm}$ distal to the hepatic flexure on the anti-mesenteric border (Figure 2). No diverticulae, signs of ischemia or necrosis, foreign bodies, palpable masses or hard fecal matter was noted. After a thorough lavage, a right hemicolectomy and ileo-transverse anastomosis was performed. The patient expired day 4 post operation form multi-organ dysfunction. Histologic examination of the specimen revealed no evidence of inflammatory bowel disease, no signs of ischemia or necrosis, the broken ends of the muscle are regular with non-specific changes in the mucosa (Figures 3-5).

\section{Discussion}

Idiopathic perforation of the colon is defined as a spontaneous perforation of the colon in the absence of disease. In 1872, it was first reported by Sir Benjamin Brodie [1]. Colonic perforations are usually the result of diverticulitis, malignancy, inflammatory bowel

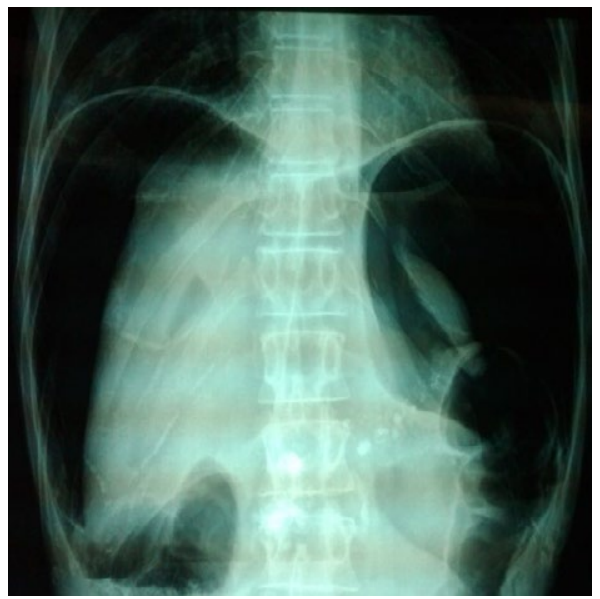

Figure 1. Abdominal X-ray showing pneumoperitoneum and pancreatic calcification.

Correspondence to: Dr. Shariful Islam, MBBS, DM, General Surgery, San Fernando General Hospital; Trinidad \& Tobago, West Indies, Tel: 868-797-4951; E-mail: shar_islam7@hotmail.com

Key words: idiopathic colonic perforation, adult

Received: August 10, 2015; Accepted: September 04, 2015; Published: September 08, 2015 


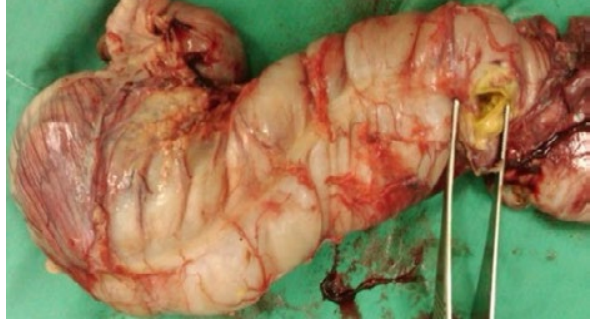

Figure 2. Right hemicolectomy specimen showing a $2 \mathrm{~cm}$ perforation on the antimesenteric border of the proximal transverse colon.

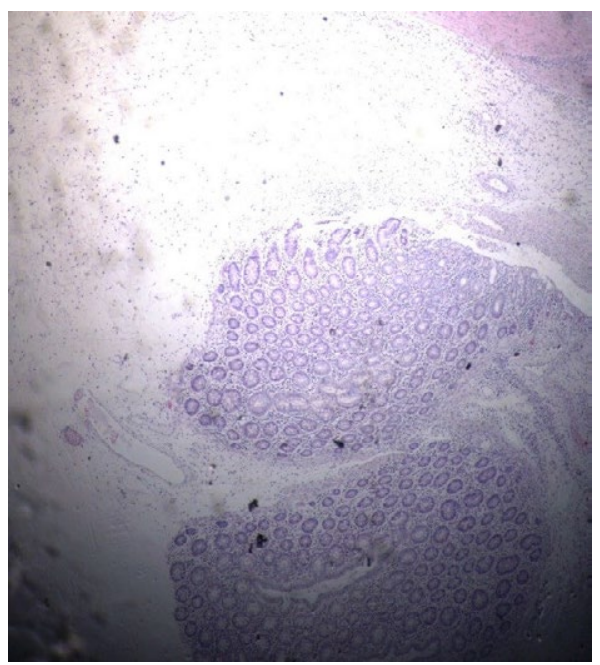

Figure 3. Microscopic view of serosa.

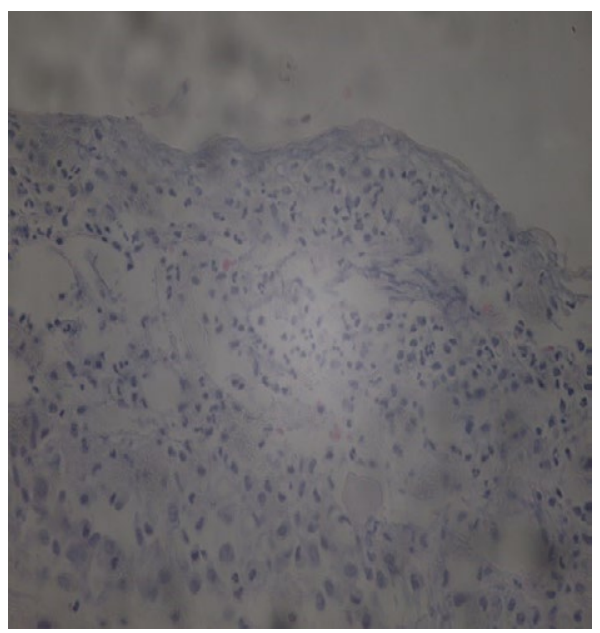

Figure 4. Microscopic view of serosa.

disease, trauma, foreign bodies or they may be iatrogenic secondary to instrumentation. Spontaneous colonic perforations have also been caused by hard feces and are classified as stercoral perforations [2]. Stercoral perforations are the result of prolonged pressure on the bowel wall caused by hard impacted feces resulting in ischemia, necrosis and eventual breakdown of the bowel wall. This results in a defect with necrotic edges and a characteristic round to ovoid ulcer [2]. True idiopathic perforation of the colon have no identifiable cause and therefore, this diagnosis cannot be made on initial presentation.

The prevalence of idiopathic colonic perforation favors the elderly with the average age of occurrence being 60 years with a male predilection $[3,4]$. As expected, patients usually present with symptoms and signs of peritonitis, with a pneumoperitoneum seen on X-ray in $<50 \%$ of patients [5]. The most common site of perforation occurs in the sigmoid colon (53.6\%), followed by the transverse colon. The perforation usually occurs on the antimesenteric border of the bowel $[4,6]$. The defect tends to be linear with a normal appearing colonic wall [3].

As previously mentioned, the etiology and therefore pathogenesis is unknown. It is postulated by some authors that certain conditions may increase the risk of having idiopathic perforation. Chronic constipation may be associated with a higher risk of idiopathic perforation. In one retrospective analysis of cases it was noted to be present in $68.8 \%$ of patients [4]. It has also been theorized that increased intraabdominal pressure may be a risk factor, some patients may have developed a perforation while straining during defecation or urination [3].

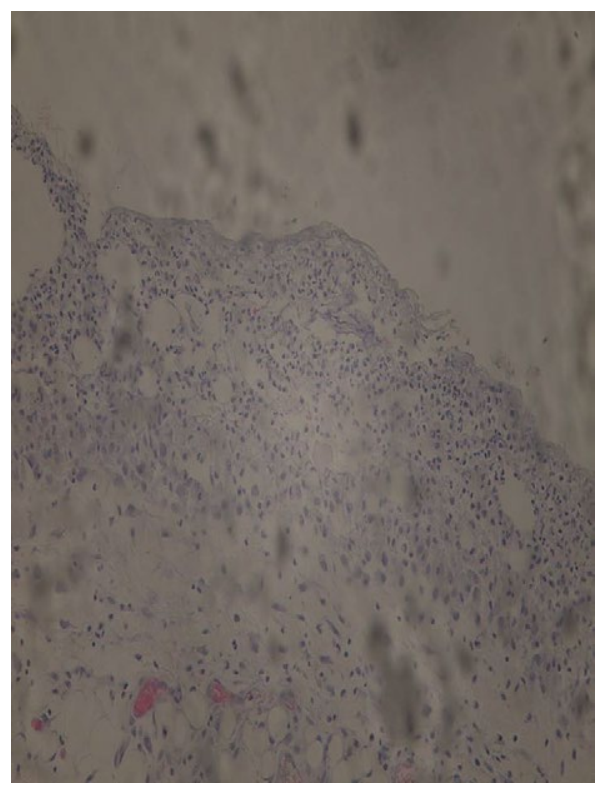

Figure 5. Microscopic view of mucosa.

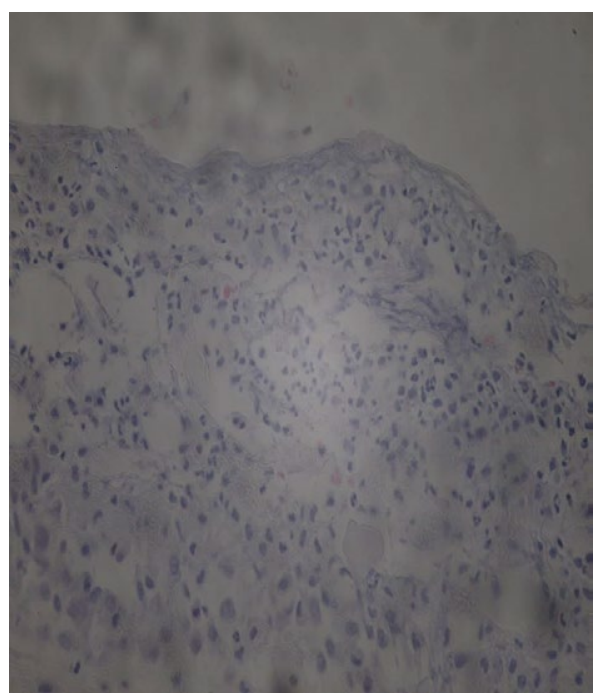

Figure 6. Microscopic view of serosa. 
Association of non-steroidal anti-inflammatory drug use has also been called into question [7]. Although many possible attributing factors have been described, causality has yet to be established.

The mortality of idiopathic colonic perforation is due to the resulting fecal peritonitis, which can range from $35-45 \%$ with some authors estimating a higher mortality $[3,4,8]$. The key to management depends on early recognition of a perforation, adequate resuscitation with minimal delay to exploratory laparotomy. The type of surgery performed may vary depending on the stability of the patient, the site and size of the lesion as well as the differential diagnosis of the managing surgeon. Hartman's procedure, primary closure, resection anastomosis with or without covering colostomy have all been described [9]. Ultimately, the decision lies with the managing surgical team.

\section{Conclusion}

Idiopathic colonic perforation is an extremely rare disease. It is entirely possible, that due to its rarity, the exact etiology and pathogenesis remains has not been elucidated. Management of this disease depends on rapidly identifying the presence of a perforation and prompt surgical treatment to reduce mortality form the sequelae of fecal peritonitis.

\section{References}

1. Goligher J, Duthie H, Nixon H (1984) Surgery of anus rectum and colon. East Sussex BN21: BailliereTindall.

2. Huttunen R, Heikkinen E, Larmi TK (1975) Stercoraceous and idiopathic perforations of the colon. Surg Gynecol Obstet 140: 756-760. [Crossref]

3. Kasahara Y, Matsumoto H, Umemura H, Shirafa S, Kuyama T (1981) Idiopathic perforation of the sigmoid colon in Japan. World J Surg 5: 125-130. [Crossref]

4. Namikawa T, Ozaki S, Okabayashi T, Dabanaka K, Okamoto K, et al. (2011) Clinical characteristics of the idiopathic perforation of the colon. J Clin Gastroenterol 45: e826e86. [Crossref]

5. Gordon PH, Nivatvon S (2007) Principles and practice of surgery for colon, rectum and anus. Complications of colonic disease and their management. New York, USA: Informa Healthcare 1150-1151.

6. Maurer CA, Renzulli P, Mazzucchelli L, Egger B, Seiler CA, et al. (2000) Use of accurate diagnostic criteria may increase incidence of stercoral perforation of the colon. Dis Colon Rectum 43: 991-998. [Crossref]

7. Ervens J, Schiffmann L, Berger G, Hoffmeister B (2004) Colon perforation with acute peritonitis after taking clindamycin and diclofenac following wisdom tooth removal. $J$ Craniomaxillofac Surg 32: 330-334. [Crossref]

8. Biondo S, Parés D, Martí Ragué J, De Oca J, Toral D, et al. (2002) Emergency operations for nondiverticular perforation of the left colon. Am J Surg 183: 256-260. [Crossref]

9. Sanjot B Kurane, Basappa T Kurane (2011) Idiopathic Colonic Perforation in Adult-A Rare Case. Indian J Surg 73: 63-64. [Crossref]

Copyright: (C2015 Islam S. This is an open-access article distributed under the terms of the Creative Commons Attribution License, which permits unrestricted use, distribution, and reproduction in any medium, provided the original author and source are credited. 